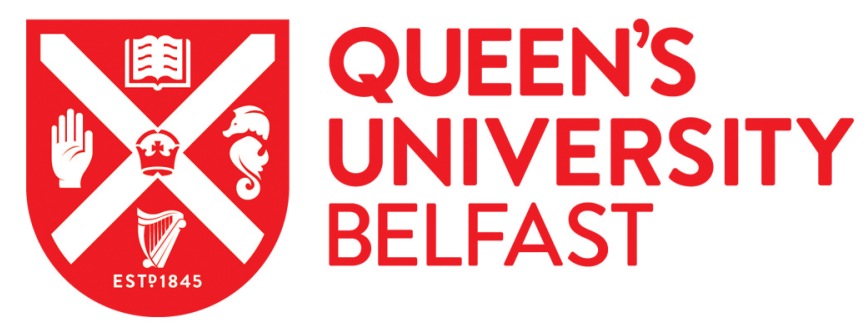

\title{
Residential Battery Energy Storage Sizing and Profitability in the Presence of PV and EV
}

Mohamed, A. A. R., Best, R., Liu, X. A., \& Morrow, D. J. (2021). Residential Battery Energy Storage Sizing and Profitability in the Presence of PV and EV. In 2021 IEEE Madrid PowerTech: Proceedings Institute of Electrical and Electronics Engineers Inc.. https://doi.org/10.1109/PowerTech46648.2021.9494792

\section{Published in:}

2021 IEEE Madrid PowerTech: Proceedings

\section{Document Version:}

Peer reviewed version

\section{Queen's University Belfast - Research Portal:}

Link to publication record in Queen's University Belfast Research Portal

Publisher rights

Copyright 2021 IEEE. This work is made available online in accordance with the publisher's policies. Please refer to any applicable terms of use of the publisher.

\section{General rights}

Copyright for the publications made accessible via the Queen's University Belfast Research Portal is retained by the author(s) and / or other copyright owners and it is a condition of accessing these publications that users recognise and abide by the legal requirements associated with these rights.

Take down policy

The Research Portal is Queen's institutional repository that provides access to Queen's research output. Every effort has been made to ensure that content in the Research Portal does not infringe any person's rights, or applicable UK laws. If you discover content in the Research Portal that you believe breaches copyright or violates any law, please contact openaccess@qub.ac.uk. 


\title{
Residential Battery Energy Storage Sizing and Profitability in the Presence of PV and EV
}

\author{
Ahmed A. Raouf Mohamed, Robert J. Best, Xueqin Liu, D. John Morrow \\ EPIC Research Cluster, School of Electronics, Electrical Engineering and Computer Science, \\ Queen's University Belfast \\ Belfast, UK
}

\begin{abstract}
Residential battery energy storage systems (BESS) are having an important role in transitioning towards low carbon communities. However, BESS capital cost remains questionable. In this work, an optimization-based BESS sizing algorithm is developed to maximize the customer's profitability by minimizing the electricity import for 162 combinations of demand, solar photovoltaic (PV) and electric vehicle (EV). The sizing algorithm results are utilized in introducing empirical formulas that ease the determination of the near-optimal BESS capacity. The annual savings are quantified for various cases under different tariff rates and the BESS viability is investigated for new installations over the next 10 years. The results show that the residential BESS can be profitable in the UK starting from 2024 without any subsidy for the time of use tariffs.
\end{abstract}

Index Terms - Battery energy storage systems, electric vehicles, photovoltaics, profitability analysis, scheduling

\section{INTRODUCTION}

The deployment of low carbon technologies (LCTs) such as PV rooftop cells, electric vehicles (EV), and heat pumps in modern distribution networks is rapidly increasing due to their various benefits and the global trend towards sustainable development goals and the net-zero emissions targets [1]. From the consumer perspective, the primary purpose of deploying these technologies is often to minimize the cost of energy. Solar PV can be very attractive due to the feed-in-tariff and export tariff programs which have motivated many consumers to install PV units. However, these tariffs have been reduced and are not as attractive as they once were. Therefore, many prosumers are looking to battery energy storage systems (BESS) as an attractive option to store their excess PV generation during the daytime and use this energy during peak periods to minimize the cost of energy. Moreover, the presence of EV supports the idea of installing BESS, as efficient energy arbitrage can be achieved.

In the next few years, the existence of batteries will be vital to accelerate the transition into low carbon economies. Outcomes from the New Thames Valley Vision project [2] and SoLa BRISTOL project [3] showed the capability of BESS in facilitating the connection of LCTs as well as delivering financial benefits to customers. Recent findings from the Barnsley virtual power plant project by Northern Powergrid [4], have shown the effectiveness of residential BESS in shaving the peak demand averagely by $65 \%$ as well as reducing the impact

This work is part of SPIRE 2 project (Storage Platform for the Integration of Renewable Energy), supported by the European Union's INTERREG VA Programme, managed by the Special EU Programmes Body (SEUPB). The views and opinions expressed in this paper do not necessarily reflect those of the European Commission or the SEUPB. of residential solar PV export power by an average of $38 \%$. The residential BESS proved the capability to flatten the substation demand profile and giving the distribution system operator (DSO) flexibility in regulating the voltage by about $0.6 \%-1.4 \%$.

Several studies have addressed residential BESS sizing, operation, and profitability. In [5], Mixed-Integer Linear Programming is employed for residential BESS system sizing to leverage the financial benefits. In [6], an energy management model based on convex programming is introduced to size the residential BESS with PV to maximize the installation profitability. Another BESS sizing method is presented in [7], the study considered different types of loads, and electricity rates in determining the optimal size of renewable generation - BESS system for a smart household. The heat-pump loading as well as PV generation were considered for BESS sizing in [8]. In [9], a residential BESS sizing approach is proposed to maximize the net present value at the end of BESS lifetime in presence of PV for two tariff structures. Economic analysis for the installations of residential BESS equipped with PV can be found in [10]. The profitability of second use EV batteries for domestic applications was demonstrated in [11]. Managing residential BESS to benefit both the customers and the DSO has been addressed in [12].

Although many studies have addressed the sizing and operation of domestic BESS, there are still some gaps in the literature, which are summarized as follows: (a) Some studies focused on sizing the BESS assuming that the BESS lifetime is more than 10 years which is impractical, as the BESS lifetime provided in the market is around 10 years. (b) Other studies considered only the solar PV and did not consider other evolving LCTs such as EV. (c) The viability of BESS at the residential level with different LCTs combinations for different tariff structures has not been investigated clearly in the literature.

Motivated by these gaps, this work addresses the residential BESS sizing and profitability in presence of PV and EV. The main contributions are summarized as follows: (a) Proposing BESS sizing algorithm to minimize the energy cost by increasing the PV self-consumption and reducing the import as well as reducing the BESS capital cost. (b) Introducing empirical formulas using multiple linear regression that can be used easily to determine the near-optimal BESS capacity, which has not been previously introduced. (c) Analyzing the profitability of deploying BESS at the time being for various combinations of LCTs under different tariff structures and answers the question 
of when the BESS should be installed to be a viable economicattractive option in the UK. The paper is organized as follows: The BESS sizing algorithm and results are presented in Section II. Section III introduces the BESS scheduling and profitability analysis. Finally, the conclusion is given in Section IV.

\section{BESS SIZING ALGORITHM}

In this work, the proposed algorithm focuses on minimizing the residential energy cost using the minimal BESS capacity to reduce the installation cost. This is achieved by finding the optimal minimum daily energy that should be distributed over the daytime-points from BESS that minimizes the daily electricity cost through a profitable energy arbitrage by charging during PV time or during night low time of use (ToU) tariff and discharge during the peak periods. Different optimization solvers can be used for this type of problems. In this paper, the selection of the optimizer was determined based on the results and the execution time which allows for simulating many case studies in a reasonable time. Hence, the European NLP solver (WORHP) [13] has been adopted due to its effectiveness in providing optimal solutions in a short execution time. The WORHP adopts sequential quadratic programming and interior point method to solve convex and nonconvex problems efficiently.

The BESS model is constructed by considering the following parameters: 1) Maximum capacity: this can be based on the maximum capacity of residential BESS available in the market, however in this algorithm, it is not limited so as to obtain a relationship between the change in demand with different LCTs combinations and the BESS capacity. 2) Power rating: this is limited to $5.5 \mathrm{~kW}$ as most of the residential BESS in the market have a maximum rating equal to or less than this value. 3) Depth of the discharge (DoD): it is known that lithium-ion batteries have high values of DoD around $90 \%$. In the proposed algorithm, the DoD is neglected as the sizing result of the proposed algorithm is the usable BESS capacity. The results are then increased by $10 \%$ to get the actual capacity from usable capacity with a DoD of $90 \%$. 4) BESS system efficiency: the power handled by the BESS through the power conversion system (PCS) is constrained by the input/output efficiency of the BESS and the PCS which is taken as 95\%. 5) Number of cycles: most of the market-based batteries have a lifetime number of cycles that exceed 4,000 cycles, which is adequate, assuming the battery completes one cycle per day and the lifetime warranty is 10 years. 6) Battery degradation: in this study, it is assumed that the BESS capacity is kept constant through its operation as the algorithm is executed for one year. Thus, degradation is not considered for the sizing algorithm, but the yearly markdown in savings due to degradation is included in the BESS profitability analysis using a Li-ion BESS degradation model. The market BESS specs can be found in several references such as [14]. The sequential steps of the sizing algorithm are as follows:

1) The algorithm reads the measurements of the demand, $P V$ power, EV charging in addition to the BESS model data.

2) For $T$ number of time-points of a day, a set of decision variables $x=\left(x_{1}, \ldots, x_{T}\right)$ is developed for the BESS (dis)charging power values to be distributed over the day. The lower and upper bounds of these variables are constrained by maximum BESS output $\left(P_{m}^{b}=5.5 \mathrm{~kW}\right)$ :

$$
-P_{m}^{b} \leq x \leq P_{m}^{b}
$$

Such that the BESS charging power $P_{t}^{c h r} \in(x>0)$ and the BESS discharging powe $P_{t}^{\text {dis }} \in(x<0)$.

3) These variables are used to obtain the BESS power with the BESS system efficiency $\left(\eta_{b}\right)$ at time-point $t$ as:

$$
P_{t}^{c h}=\frac{P_{t}^{c h r}}{\eta_{b}} ; \quad P_{t}^{d i}=P_{t}^{d i s} \eta_{b}
$$

4) Then these values are used to determine the household net power $\left(P_{t}^{\text {net }}\right)$ at time-point $t$ :

$$
P_{t}^{n e t}=P_{t}^{d}+P_{t}^{E V} \pm P_{t}^{b}-P_{t}^{P V}
$$

Where $P_{t}^{d}$ is the demand value, $P_{t}^{E V}$ is the EV charging power, $P_{t}^{P V}$ is the $\mathrm{PV}$ generation output, and $P_{t}^{b}$ is the BESS power such that $P_{t}^{b} \in\left\{P_{t}^{c h}, P_{t}^{d i}\right\}$.

5) The value of $P_{t}^{\text {net }}$ for each time-point of the day are used to evaluate the following bi-objective function:

$$
\begin{aligned}
& \min \left(\left(w_{1} \sum_{t=1}^{T} \rho_{t}^{e}\left(P_{t}^{n e t} \tau\right)\right)+w_{2} \rho^{b} E_{u s}^{b}\right) \\
& \text { s.t. } \quad E_{u s}^{b}=\sum_{t=1}^{T_{c}} P_{t}^{c h r} \tau \vee \sum_{t=1}^{T_{d}} P_{t}^{d i s} \tau
\end{aligned}
$$

Where $T$ is the number of points of a day that represents the optimization horizon, $\rho_{t}^{e}$ is the electricity price per $\mathrm{kWh}, \tau$ is the time-step and calculated according to the data resolution as $\tau=\frac{d m}{60}$, where $d m$ is the data resolution in minutes (e.g., $d m=10$ for 10-minute resolution, 60 for 1 -hour resolution), $\rho^{b}$ is the BESS price per $\mathrm{kWh}$, and $E_{u s}^{b}$ is the usable BESS capacity in kWh. The previous objective functions are given the same priority using the weighted sum method $\left(w_{1}=w_{2}=0.5\right)$ and converted into a mono-objective function by normalization using the consequent upper-bound approach [15].

6) At the end of each iteration, the algorithm updates the solutions according to the evaluated objective function to optimally allocate the BESS (dis)charging power while satisfying the power balance expressed as:

$$
\sum_{t=1}^{T} x_{t}=0 \quad ; \quad \sum_{t=1}^{T_{c}} P_{t}^{c h r}=\left|\sum_{t=1}^{T_{d}} P_{t}^{\text {dis }}\right|
$$

Where $T_{c}$ and $T_{d}$ are the charging/discharging periods. This constraint is introduced assuming that the BESS completes one cycle daily to minimize the electricity bill by maximizing the energy arbitrage using the PV excess generation and ToU tariff. To ensure that the BESS completes only one cycle daily, the discharging is constrained by the peak period (5:00 PM to 12:00 AM), while the charging is conducted during the rest of the day (during PV period and night-time low ToU rate period).

7) The algorithm terminates when the WORHP converges and obtains optimal solutions. The algorithm outputs are the BESS (dis)charging power values and corresponding time-points which are used to determine daily the optimal BESS capacity using Eq. (5). 
It is noteworthy that, the PV and the EV power are not part of the algorithm decision variables since we consider an existing PV and EV, hence the algorithm aims to minimize the customer's energy costs by adding a storage system. The sizing algorithm uses the ToU electricity prices from the Economy 7 rates in Northern Ireland; $18.11 \mathrm{p} / \mathrm{kWh}$ during daytime rate, and $10.13 \mathrm{p} / \mathrm{kWh}$ during the night rate from 1:00 am to 8:00 am [16], this tariff is used due to its popularity among customers. While the exporting tariff is taken $5 \mathrm{p} / \mathrm{kWh}$ as an average value based on the new UK Smart Export Guarantee program. Due to the fact that the LCTs profiles are changing dramatically on a daily basis, it is difficult to determine a specific optimal BESS size for a household. Thus, the algorithm is implemented for one year and then, the optimal daily values are used to calculate an annual average BESS capacity. One-year data are obtained to cover different households' cases categorized as follows:

\section{A. Household load profiles}

Different load profiles for 18 households were imported from the half-hourly smart meter measurements in [17], covering the full year of 2013 to simulate different UK domestic consumption categories [18] given in Table I (6 households/category).

TABLE I. TYPICAL DOMESTIC CONSUMPTION IN THE UK

\begin{tabular}{ccc}
\hline $\begin{array}{c}\text { Consumption } \\
\text { Category }\end{array}$ & $\begin{array}{c}\text { Typical consumption } \\
\mathrm{kWh} / \text { year range }\end{array}$ & $\begin{array}{c}\text { Case Study } \\
\mathrm{kWh} / \text { day range }\end{array}$ \\
\hline Low & $<4,200$ & $3.62-10.93$ \\
\hline Medium & $4,200<7,100$ & $12.83-18.23$ \\
\hline High & $\geq 7,100$ & $19.60-33.82$ \\
\hline
\end{tabular}

\section{B. EV charging profiles}

The EV charging is closely related to people's behaviour; hence, it is difficult to adopt a specific model to generate EV patterns as they require many assumptions such as the number of trips, distances, and other information based on surveys. Hence, to avoid any unwanted assumptions, actual charging measurements from the UK are used. These measurements are categorized according to the charger type. Six different EV profiles with 10-minute resolution were obtained from [19], covering the full year of 2013 to simulate the $3 \mathrm{~kW}$ standard charger ( 3 profiles) and the $7 \mathrm{~kW}$ fast charger ( 3 profiles).

\section{PV generation profiles}

Two popular PV system sizes were considered; $3.68 \mathrm{~kW}$ and $6.5 \mathrm{~kW}$, their actual generation profiles in 5-minute resolution were obtained for two houses in Northern Ireland from [20].

\section{BESS Sizing Results}

The data used for simulations are categorized into three sets, each set contains six different load profiles (two for each demand category). For each set, two different EV charging measurements are used. For each household's load profile, nine applicable combinations are investigated: 1) Demand only, 2) Demand + $3.68 \mathrm{~kW}$ PV , 3) Demand $+6.5 \mathrm{~kW}$ PV, 4) Demand $+3 \mathrm{~kW} \mathrm{EV}$, 5) Demand $+7 \mathrm{~kW} E V, 6$ ) Demand $+3.68 \mathrm{~kW} \mathrm{PV}+3 \mathrm{~kW} \mathrm{EV}$, 7) Demand + $3.68 \mathrm{~kW} \mathrm{PV}+7 \mathrm{~kW} \mathrm{EV}, 8)$ Demand $+6.5 \mathrm{~kW} \mathrm{PV}$ $+3 \mathrm{~kW} \mathrm{EV}$, and 9) Demand $+6.5 \mathrm{~kW} \mathrm{PV}+7 \mathrm{~kW}$ EV. This is equivalent to 162 households. A one-year simulation is implemented for each household, in each day the algorithm obtains the daily optimal BESS usable capacity. At the end of the year, the average optimal BESS usable capacity is obtained. The BESS capacities are then increased by $10 \%$ to represent the actual capacity with $90 \% \mathrm{DoD}$, the sizing results are shown in
Fig. 1, and an example of the daily operation is shown in Fig. 2 for a household of $10 \mathrm{kWh} /$ day, $3.68 \mathrm{~kW} \mathrm{PV}$, and $3 \mathrm{~kW} \mathrm{EV}$.
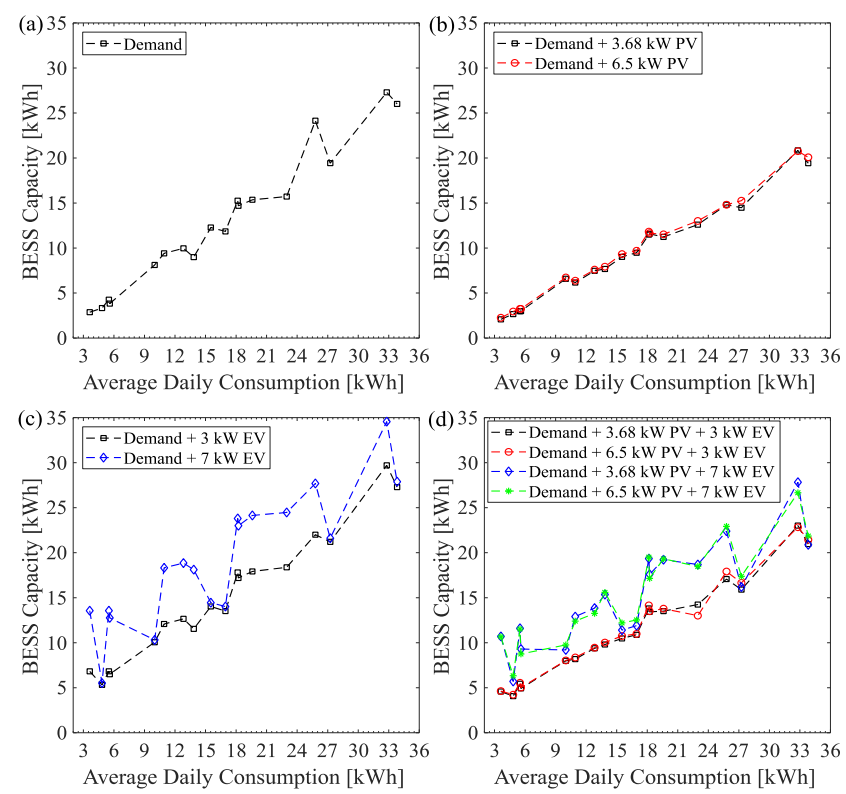

Figure 1. BESS sizing results for 162 different combinations. (a) Demand only, (b) Demand + PV, (c) Demand + EV, (d) Demand + PV + EV

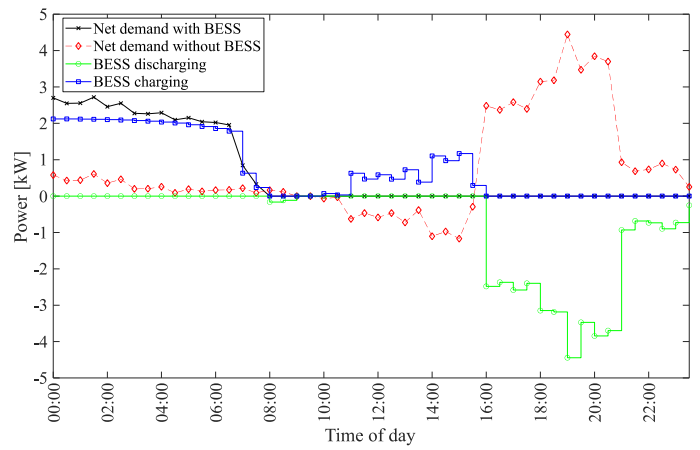

Figure 2. An example of the daily operation for a household

The results in Fig. 1 show that the BESS capacity changes with the change in demand consumption and LCTs. This change is based on two main factors associated with the load and LCT profiles; the daily average consumption/generation, and the net profile shape which includes the load variations and peak to average difference. Furthermore, all houses with EV required bigger sizes to minimize the energy cost, by discharging the BESS during the peak and charging using the PV or during low ToU tariff period when there is no PV installed or the PV generation is insufficient. Moreover, the results show that the existence of PV leads to smaller BESS capacities compared to the base demand. This because in the presence of the PV, the demand is satisfied using PV power during daytime, hence, the residual demand of the day to be shaved is decreased. Without PV, the BESS will have to shave a larger demand area during the high ToU tariff period, hence a larger BESS is required.

Additionally, it is observed that the BESS size does not increase with the increase in PV size especially in the presence of EV, as some households with the same daily consumption were found to require smaller BESS sizes for the $6.5 \mathrm{~kW}$ PV with respect to the $3.68 \mathrm{~kW} \mathrm{PV}$. This is because smaller PV systems do not always produce enough energy to satisfy the demand and 
charge the BESS during daytime, particularly during the winter. Hence, a larger BESS is required to optimize the ToU tariff by charging during the night low ToU tariff and discharging during the peak to minimize the total energy cost. Moreover, the difference between the BESS sizes obtained for the two PV systems is minor as the mean absolute percentage error is $3.43 \%$.

From the BESS sizing results, the relation between the change in demand with LCTs and BESS sizes can be fitted using linear regression [21]. The demand and LCT data of the 162 households were used along with the sizing results to obtain empirical relations between the predictor variables (demand, PV, and EV) and the response variable (BESS capacity) using the multiple linear regression [21]. To produce an accurate formula, different set of predictors have been tested. The best combination is to use five predictors. These predictors are the average daily consumption $\left(E_{\text {avg }}^{d}\right)$, PV inverter rating $\left(P_{\text {max }}^{P V}\right), \mathrm{EV}$ charger rating $\left(P_{\max }^{E V}\right)$, average daily $\mathrm{PV}$ generation $\left(E_{\text {avg }}^{P V}\right)$, and average daily $\mathrm{EV}$ consumption $\left(E_{\text {avg }}^{E V}\right)$. A relation between the BESS capacity $\left(E_{a}^{b}\right)$ and these predictors can be expressed as:

$$
\begin{aligned}
E_{a}^{b}=2.657 & +0.617 E_{\text {avg }}^{d}+2.275 P_{\max }^{P V} \\
& -0.383 P_{\max }^{E V}-1.188 E_{\text {avg }}^{P V}+0.951 E_{\text {avg }}^{E V}
\end{aligned}
$$

This regression formula can be interpreted using the following metrics: R-squared: 0.968, Adjusted R-Squared: 0.967, Root Mean Squared Error: 1.18\%, p-value: 0. Another simpler formula can be produced considering only three predictors; $E_{a v g}^{d}, P_{\max }^{P V}$, and $P_{\max }^{E V}$. This formula is easier to be used, however, it is less accurate than the previous formula as it considers only the LCTs power ratings, expressed as:

$$
E_{a}^{b}=1.781+0.628 E_{\text {avg }}^{d}-0.5 P_{\max }^{P V}+0.9 P_{\max }^{E V}
$$

This model has R-squared: 0.906, Adjusted R-Squared: 0.904, Root Mean Squared Error: 2.07\%, and p-value: 0.

These formulas are introduced for customers, retailers, researchers, and technology developers to estimate roughly the near-optimal BESS size for a household in the UK without the need for power profiles and detailed measurements or stochastic optimization process. Noteworthy, the formulas' accuracy can be improved using multiple linear regression with interaction terms, however, they will become more complex to be used easily by individuals. The sizing results obtained using these formulas may contain some error; however, the BESS currently available in the market are limited to certain discrete capacities. Hence, the resultant value of these formulas should be rounded to the nearest available BESS capacity. Furthermore, these formulas should be used for double ToU tariff (DT) as the BESS sizing results were implemented using the Economy 7 tariff.

The proposed formula has been validated by obtaining BESS sizes for two similar studies presented in the literature. In [22], a household with an average daily consumption of $13.56 \mathrm{kWh}$ and $5 \mathrm{~kW}$ PV required a BESS of $8 \mathrm{kWh}$. Using Eq. (8), the obtained capacity is $7.8 \mathrm{kWh}$, with an error of $-2.5 \%$. In [10], a household with an average daily consumption of $3.5 \mathrm{kWh}$ and $3.8 \mathrm{~kW} \mathrm{PV}$ required a BESS of $2 \mathrm{kWh}$. According to Eq. (8), the optimal capacity is $2.08 \mathrm{kWh}$, with an error of $+4 \%$.

\section{Profitability ANALYSIS - CASE StUdy}

\section{A. Scheduling Algorithm}

To quantify the profitability of residential BESS, a scheduling algorithm is developed. This algorithm follows the same routine of the BESS sizing algorithm described in the previous section (Step (1) to Step (4)). However, in this algorithm the actual capacity $\left(E_{a}^{b}\right)$ and power rating are known. Hence, the algorithm aims to schedule the BESS power to minimize the electricity cost expressed as:

$$
\min \left(\sum_{t=1}^{T} \rho_{t}^{e}\left(P_{t}^{n e t} \tau\right)\right)
$$

Where $P_{t}^{\text {net }}$ is calculated using Eq. (3) and the algorithm distributes the BESS energy all over the day efficiently to achieve the objective subject to the BESS rating Eq. (1) in addition to the following constraint related to the BESS state of charge $(S o C)$ and capacity:

$$
\begin{gathered}
S o C_{b}^{\text {min }} \leq S o C_{t, b} \leq S o C_{b}^{\max } \\
S o C_{t, b}=S o C_{t-1, b}+\frac{P_{t, b}^{c h} \eta_{b} \tau}{E_{a}^{b}}-\frac{\left|P_{t, b}^{d i}\right| \tau}{E_{a}^{b} \eta_{b}} \\
E_{u s}^{b}=E_{a}^{b} \times D o D ; \quad ; o C_{\text {min }}=S o C_{\text {max }}-D o D
\end{gathered}
$$

B. Case Study

For the profitability analysis, a single house is used with daily consumption of $11.5 \mathrm{kWh}$ representing the average household consumption in Northern Ireland. The $3.68 \mathrm{~kW}$ PV $(9.78 \mathrm{kWh} /$ day) and $3 \mathrm{~kW} \mathrm{EV}(3.6 \mathrm{kWh} /$ day) are used for the analysis. The $3.68 \mathrm{~kW} \mathrm{PV}$ is used as this is the most deployed inverter size, additionally, in the UK there is a limit to the feedin power, according to the G98 connection that limits the PV exported power to $3.68 \mathrm{~kW}$ [23]. Using the empirical formula Eq. (7), BESS capacity of $8.8 \mathrm{kWh}$ is required for this household. The BESS system specifications used in the analysis are tabulated in Table II according to the nearest market capacity. The stated BESS system prices are obtained from real quotations and includes the installation, and commissioning costs.

TABLE II. BESS SPECIFICATION AND PARAMETERS USED IN THE ANALYSIS

\begin{tabular}{l|l}
\hline BESS Total Capacity [kWh] / Rating [kW] & $9.8 / 5$ \\
\hline Depth of Discharge (DoD) [\%] & 90 \\
\hline Number of cycles / Lifetime [Years] & $6,000 / 10$ \\
\hline BESS efficiency [\%] / PCS efficiency [\%] & $95 / 95$ \\
\hline BESS Price [£/kWh] / PCS price [£/kW] & $567 / 300$ \\
\hline
\end{tabular}

The scheduling algorithm is used to simulate one year to determine the annual electricity costs and savings for different tariff structures. Note that the BESS capacity was obtained using the proposed empirical formula which was determined for DT (UK Economy 7) due to its widespread deployment among the customers. Yet, another two tariff rates in the UK have been used to assess the BESS viability for different tariff structures. The three selected tariffs are; fixed/flat tariff (FT) - $18.74 \mathrm{p} / \mathrm{kWh}$ [24], DT - Economy 7 [16], and time of day tariff (TIDE) - threelevel ToU tariff [25]. The TIDE tariff was introduced by Green Energy UK in 2017 consisting of three-time of use rates (offpeak, shoulder, and peak) reflecting the grid power profile during weekdays, while it acts as a DT during the weekends. The export tariff is taken as $5 \mathrm{p} / \mathrm{kWh}$. For each tariff rate, a one-year simulation is implemented, and the yearly electricity bill and savings are quantified for six different cases; Case I: without LCT (base case for a house without EV, PV, or BESS); Case II: with EV only; Case III: with PV only, Case IV: with PV and EV; Case V: with PV and BESS, and Case VI: with PV, EV, and BESS. The results are given in Table III. 
TABLE III. ANNUAL ELECTRICITY BILL FOR DIFFERENT CASES AND TARIFFS

\begin{tabular}{c|c|c|c|c|c|c}
\cline { 2 - 7 } \multicolumn{2}{c}{} & \multicolumn{6}{c}{ Annual Electricity Cost [£] } \\
\cline { 2 - 7 } \multicolumn{2}{c|}{ Case I } & Case II & Case III & Case IV & Case V & Case VI \\
\hline FT & 767.32 & 993.48 & 320.55 & 511.10 & 237.74 & 397.15 \\
\hline DT & 713.77 & 917.04 & 276.96 & 446.24 & 70.72 & 195.44 \\
\hline TIDE & 781.99 & $1,020.43$ & 345.58 & 549.92 & 33.57 & 151.6 \\
\hline
\end{tabular}

The results show the paybacks of installing PV solar systems, BESS, and the effect of EV charging on the electricity bill. Having an EV without PV or BESS will increase the annual electricity bill on average by $29.5 \%$. While having a PV only will cut the electricity bill on average by $58.4 \%$ annually. Combining PV and EV will reduce the electricity bill on average by $48.6 \%$. While, installing BESS will reduce the electricity cost by $25.8 \%$ for the FT, $74.5 \%$ for the DT, and $90.3 \%$ for the TIDE tariff, with respect to having a $\mathrm{PV}$ only. In the presence of $\mathrm{PV}$ and $\mathrm{EV}$, the BESS reduced the electricity bill by $22.3 \%$ (FT), $56.2 \%$ (DT), and $72.4 \%$ (TIDE tariff).

Residential BESS profitability is a debatable subject as currently the lifetime of most domestic BESS is 10 years, which makes it unattainable to pay back the capital investment. However, other factors should be considered as they may play an important role in accelerating the payback of the residential BESS such as the increase in the electricity prices and the decline in BESS prices. In this study, the payback period is quantified for different deployment cases. To do that, some factors and rates are considered. These factors include the BESS lifetime $(L T=$ 10 years), investment discount rate $\left(d i s_{r}=4 \%\right)$ [22], and UK electricity price average yearly growth rate $\left(e^{r}=5 \%\right)$ [26]. Additionally, the declining in savings due to BESS degradation has been quantified using several methods, and the results were comparable. These methods include the use of fixed annual operation and maintenance (O\&M) costs, savings degradation rate [9], and Li-ion degradation [27]. The presented results adopt the degradation factor $(L)$ obtained from the degradation model [27], representing the yearly loss percentage in capacity/revenue in addition to a yearly O\&M rate $\left(o^{r}=1.5 \%\right)$ of the yearly capacity loss cost, this rate is introduced in agreement with the PV O\&M by BEIS [28] to cover the O\&M due to degradation and to compensate any error in the results obtained from the degradation model. The total savings $(T S)$ can be expressed as:

$$
T S=\sum_{n=1}^{L T} \frac{\left(C_{n}-C_{n}^{b}\right)\left(1+e^{r}\right)^{n}\left(1-L_{n}\right)-o^{r} L_{n} \rho^{b}}{\left(1+d i s_{r}\right)^{n}}
$$

Where $C_{n}$ is the yearly electricity bill without BESS, and $C_{n}^{b}$ is the yearly electricity bill in the presence of the BESS. Then, the net present value $(N P V)$ and the annual return on investment $(A R O I)$ at the end of the BESS lifetime are calculated considering the system capital expenditures $(C E X)$ as:

$$
\begin{gathered}
C E X=\rho^{b} E_{a}^{b}+\rho^{P C S} P_{m}^{b} \\
N P V=T S-C E X \\
A R O I=\frac{N P V}{L T \times C E X}
\end{gathered}
$$

The TS, NPV, AROI, and optimal year for installation for different cases and tariff rates are tabulated in Table IV. As given in Table IV, deploying the BESS with FT leads to poor results. For the DT, the results improved but are not attractive compared to the TIDE results. The TIDE is the best tariff structure for PVBESS system owners as the results are promising. Noteworthy, the BESS is more beneficial in the presence of PV and EV as the energy arbitrage is maximum and will shorten the payback period with better NPV and AROI. The TS is the BESS system CEX to breakeven in 10 years and is in the range of $£ 683-£ 3869$ according to the tabulated cases. Clearly given the current BESS CEX is not an economic-effective for UK customers.

TABLE IV. BESS PROFITABILITY ANALYSIS RESULTS

\begin{tabular}{l|c|c|c|c}
\hline $\begin{array}{l}\text { Tariff } \\
\text { Structure }\end{array}$ & $\begin{array}{c}\text { TS } \\
{[£]}\end{array}$ & $\begin{array}{c}\text { NPV } \\
{[£]}\end{array}$ & $\begin{array}{c}\text { AROI } \\
{[\%]}\end{array}$ & $\begin{array}{c}\text { Optimal Year } \\
\text { for installation }\end{array}$ \\
\hline \multicolumn{5}{c}{ Case V - PV + BESS } \\
\hline FT & 682.4 & $-6,373.6$ & -9.03 & N/A \\
\hline DT & $1,816.5$ & $-5,239.5$ & -7.43 & 2027 \\
\hline TIDE & $2,788.4$ & $-4,267.6$ & -6.05 & 2025 \\
\hline \multicolumn{5}{c}{ Case VI - PV + BESS + EV } \\
\hline FT & 968.5 & $-6,087.5$ & -8.63 & 2030 \\
\hline DT & $2,225.9$ & $-4,830.1$ & -6.85 & 2026 \\
\hline TIDE & $3,581.4$ & $-3,474.6$ & -4.92 & 2024 \\
\hline
\end{tabular}

To determine when in the future a new BESS installation is likely to be economically viable, another factor is considered. This factor is related to BESS prices, in this work, the analysis was performed for the next 10 years for the three tariff rates with a yearly BESS price declining rate of $18 \%$ per $\mathrm{kWh}$ [29]. The results show that in the existence of PV only, the installation of BESS will be profitable starting from 2025 for TIDE, 2027 for DT and is not attractive in the next 10 years for the FT. While the presence of the EV maximizes the energy arbitrage by allowing the installation of the BESS to pay back in 10 years by 2024 for TIDE, 2026 for DT and 2030 for the FT.

The FT is not effective and should not be adopted by PVBESS owners within the next 10 years. The DT is more attractive as the BESS investment could be profitable starting from 2026. The TIDE is very promising as it allows the BESS investment to breakeven starting from 2024 with positive NPV and AROI. It is highly recommended for electricity suppliers and regulators to introduce flexible bespoke tariffs representing the grid profile shape and its necessities such as the TIDE to indirectly enforce consumers to adjust their consumption to maximize their savings and encouraging the deployment of LCTs and BESS which supports the network and hastens the transition towards the netzero target. The results for TIDE and DT are shown in Fig. 3.

Regarding solar PV, the exporting power is limited in the UK by the G98 connection standard. Moreover, the UK feed-in tariff has been stopped in March 2019 as is the case in Spain and the Republic of Ireland. Hence, PV systems below $4 \mathrm{~kW}$ are more attractive for low/medium consumption households which also reduces the PV system CEX. Additionally, larger than $3.68 \mathrm{~kW}$ inverter connection requires hard assessments by the DSO to get the connection permission as well as extra costs associated with this connection. The previous analysis was done to determine the profitability of the BESS system assuming that the household has already a PV unit. To quantify the profitability and payback of PV systems only without BESS, a cost of $£ 7,000$ is considered for the $3.68 \mathrm{~kW}$ system including all the capital expenditures according to the prices in the UK market with 20 years lifetime. Module degradation rate of $(0.5 \%)$ per annum, O\&M annual fixed cost (1.5\%) of PV CEX [28], discount rate (4\%), and electricity growth rate of $(5 \%)$ are used. The results show that the PV systems are very attractive to be installed nowadays as 
they can pay back in 15 years on average under different tariff structures and LCTs combinations. Noteworthy, this was determined based on an export tariff only with no other subsidy.

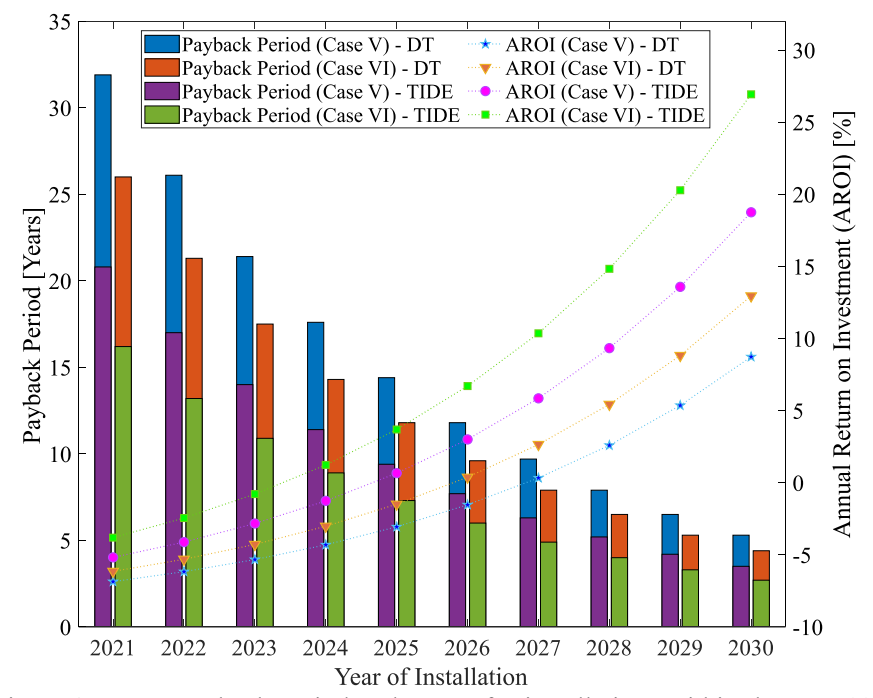

Figure 3. BESS payback period and AROI for installations within the next 10 years

\section{CONCLUSION}

This work proposed a BESS sizing algorithm to determine the optimal size of residential batteries in the presence of PV and EV that minimizes the energy and installation costs. The algorithm was implemented for 162 scenarios covering different demand and LCT combinations. The study showed the potential of formulating empirical formulas to aid the determination of near-optimal BESS capacity based on the sizing algorithm results using multiple linear regression. These formulas are very appealing due to the simplicity associated with their usage unlike the several published methods that require many measurements which may not be available. The economic viability of installing residential BESS was investigated for various cases and tariff structures. The results show that deploying battery systems with 10 years lifetime is currently not an attractive option for UK customers as the net present value and return on investment are negative for all the tariff structures. The study also investigated the time horizon for profitable BESS investment, and the results show that the BESS could be a gainful option starting from 2024 for TIDE tariff. The study suggests regulating the flexible bespoke time of use tariffs such as TIDE to encourage consumers to install BESS and adjust their consumption. To accelerate the deployment in the short-term, direct subsidy can be offered or by reducing the taxes and interest rates on loans.

\section{REFERENCES}

[1] A. A. R. Mohamed, D. J. Morrow, and R. Best, 'The Deployment of Low Carbon Technologies in Modern Distribution Networks', presented at the 2019 IEEE PES Innovative Smart Grid Technologies Europe (ISGT-Europe), Bucharest, Romania, 2019, pp. 1-5.

[2] SSEN, 'Project Closedown Report - NEW Thames Valley Vision', 2017. [Online]. Available: https://rb.gy/wavfml

[3] WPD, 'Sola Bristol Project Closedown Report', Ofgem, 29-Apr-2016. [Online]. Available: https://www.ofgem.gov.uk/publications-andupdates/wpd-s-sola-bristol-project-closedown-report. [Accessed: 20Aug-2020]

[4] P. Hadjiodysseos, S. Van Limpt, and A. Alexeev, 'Distributed Storage and Solar Study', CIRED, 2019.
[5] M. Starke et al., 'Development and analysis of an energy storage sizing tool for residential deployment', in 2017 IEEE Power \& Energy Society General Meeting, 2017, pp. 1-5.

[6] X. Wu, X. Hu, X. Yin, C. Zhang, and S. Qian, 'Optimal battery sizing of smart home via convex programming', Energy, vol. 140, pp. 444453, 2017.

[7] S. Kahrobaee, S. Asgarpoor, and W. Qiao, 'Optimum sizing of distributed generation and storage capacity in smart households', IEEE Transactions on Smart Grid, vol. 4, no. 4, pp. 1791-1801, 2013.

[8] J. von Appen and M. Braun, 'Sizing and improved grid integration of residential PV systems with heat pumps and battery storage systems', IEEE Trans. on energy conversion, vol. 34, no. 1, pp. 562-571, 2019.

[9] R. Tang, B. Yildiz, P. H. Leong, A. Vassallo, and J. Dore, 'Residential battery sizing model using net meter energy data clustering', Applied Energy, vol. 251, p. 113324, 2019.

[10] K. Panagiotou, C. Klumpner, and M. Sumner, 'Sizing guidelines for grid-connected decentralised energy storage systems: single house application', The Journal of Engineering, vol. 2019, no. 17, pp. 3802 3806, 2019.

[11] R. Madlener and A. Kirmas, 'Economic viability of second use electric vehicle batteries for energy storage in residential applications', Energy Procedia, vol. 105, pp. 3806-3815, 2017.

[12] A. A. R. Mohamed, R. J. Best, X. Liu, and D. J. Morrow, 'Domestic Battery Power Management Strategies to Maximize the Profitability and Support the Network', IEEE PES General Meeting, 2021, pp. 1-5 accepted to be published

[13] C. Büskens and D. Wassel, 'The esa nlp solver worhp', in Modeling and optimization in space engineering, Springer, 2012, pp. 85-110.

[14] 'Battery Storage Specs', Naked Solar. [Online]. Available: https://nakedsolar.co.uk/storage/

[15] R. T. Marler and J. S. Arora, 'Function-transformation methods for multi-objective optimization', Engineering Optimization, vol. 37, no. 6, pp. 551-570, 2005

[16] Power NI, 'Economy 7 Unit Rates', 2020. [Online]. Available: https://rb.gy/aeznwh. [Accessed: 18-Jul-2020]

[17] UK Power Networks, 'SmartMeter Energy Consumption Data in London Households - London Datastore'. [Online]. Available: https://rb.gy/agd2ji. [Accessed: 13-Aug-2020]

[18] Ofgem, 'Typical Domestic Consumption Values', Ofgem, 30-Jul-2015. [Online]. Available: https://rb.gy/jnkxbh. [Accessed: 20-Aug-2020]

[19] UK Power Networks, 'Low Carbon London Electric Vehicle Load Profiles - London Datastore', 2014-2013. [Online]. Available: https://rb.gy/d8eouq. [Accessed: 17-Jul-2020]

[20] PVOutput, 'PV output data', 2019. [Online]. Available: https://pvoutput.org/

[21] K. J. Preacher, P. J. Curran, and D. J. Bauer, 'Computational tools for probing interactions in multiple linear regression, multilevel modeling, and latent curve analysis', Journal of educational and behavioral statistics, vol. 31, no. 4, pp. 437-448, 2006.

[22] A. Pena-Bello, M. Burer, M. K. Patel, and D. Parra, 'Optimizing PV and grid charging in combined applications to improve the profitability of residential batteries', Journal of Energy Storage, vol. 13, pp. 58-72, 2017.

[23] Energy Networks, 'Engineering Recommendation G98'. [Online]. Available: https://rb.gy/vawbzm. [Accessed: 20-Aug-2020]

[24] Power NI, 'Electricity unit and tariff rates and prices', 2020. [Online]. Available: https://powerni.co.uk/plan-prices/compare-our-plans/tariffrates/. [Accessed: 18-Jul-2020]

[25] Green Energy, 'TIDE Tariff', 2017. [Online]. Available: https://rb.gy/eegjow

[26] N. Sonnichsen, 'UK: Electricity prices for households 2010-2019 | Statista'. [Online]. Available: https://rb.gy/8nb7bd. [Accessed: 20Aug-2020]

[27] B. Xu, A. Oudalov, A. Ulbig, G. Andersson, and D. S. Kirschen, 'Modeling of lithium-ion battery degradation for cell life assessment', IEEE Transactions on Smart Grid, vol. 9, no. 2, pp. 1131-1140, 2016.

[28] BEIS, 'Electricity Generation Costs', 2016. [Online]. Available: https://rb.gy/zkkp36

[29] Logan Goldie-Scot, 'A Behind the Scenes Take on Lithium-ion Battery Prices | BloombergNEF', 2019. [Online]. Available: https://bit.ly/3iEYCRd 